\title{
A Developed Material as a Nuclear Radiation Shield for Personal Wearing
}

\author{
Samir Ushah El-Kameesy ${ }^{1}$, Wagdy Ahmed Kansouh ${ }^{2}$, Elsayed Salama ${ }^{1,3 *}$, \\ Mabrouk Kamel El-Mansy4, Sara Ahmed El-Khateeb', Riad Mostafa Megahid² \\ ${ }^{1}$ Physics Department, Faculty of Science, Ain Shams University, Cairo, Egypt \\ ${ }^{2}$ Department of Reactor Physics, Division of Atomic Reactors, Atomic Energy Authority, Cairo, Egypt \\ ${ }^{3}$ Basic Science Department, Faculty of Engineering, British University in Egypt (BUE), El Sherouk City, Egypt \\ ${ }^{4}$ Department of Physics, Faculty of Science, University of Benha, Benha, Egypt \\ Email: *e_elsayed@sci.asu.edu.eg
}

How to cite this paper: El-Kameesy, S.U., Kansouh, W.A., Salama, E., El-Mansy, M.K., El-Khateeb, S.A. and Megahid, R.M. (2017) A Developed Material as a Nuclear Radiation Shield for Personal Wearing. Journal of Applied Mathematics and Physics, 5, 596605.

https://doi.org/10.4236/jamp.2017.53051

Received: January 17, 2017

Accepted: March 6, 2017

Published: March 9, 2017

Copyright (C) 2017 by authors and Scientific Research Publishing Inc. This work is licensed under the Creative Commons Attribution International License (CC BY 4.0).

http://creativecommons.org/licenses/by/4.0/

\begin{abstract}
A new composite of silicone rubber and boric acid was developed to be used as a personal wearing for protection from nuclear radiation. The capability of this material for absorbing thermal neutrons of different intensities followed by a detonation of nuclear weapon has been investigated. This investigation was performed by using californium-252 neutron source of like fission spectrum. The thermal neutron flux was measured behind different thicknesses of the developed material using a $\mathrm{BF}_{3}$ detector. Two positions of measurements were performed; at position near the detonation where the intensity of thermal neutron flux is low and at position far from the detonation where the intensity of thermal neutron is high. For both cases, the contribution of total thermal, initial incident and new produced thermal neutron fluxes are measured. The obtained results indicated that, addition of boron with concentration of about $17 \%$ to the silicon rubber tends to decrease the flux by more than $70 \%$.
\end{abstract}

\section{Keywords}

Neutron Shielding, Nuclear Weapon, Fission Bomb, Thermal Neutrons, Californium Source

\section{Introduction}

Materials composed of light elements are preferred for fast neutron shielding because of the large energy loss per collision. Thus, hydrogenous materials like water, rubber, polypropylene etc., are very effective for fast neutron shielding, especially of energy below $2 \mathrm{MeV}$. These materials are used to moderate fast neutrons within a small thickness to become of thermal energy so can be ab- 
sorbed by most of shielding materials. In addition, absorption of thermal neutrons is preferable to take place through the reactions in which high energy gamma rays are not emitted [1] [2]. Boron elements absorb thermal neutrons with the emission of charged particles and gamma rays of low energy, $\mathrm{E}_{\gamma}=480$ $\mathrm{keV}[3][4]$.

Heavy weight elements are the most effective for gamma shielding and at the same time degrade the energy of fast neutrons by inelastic scattering collisions with the large number of electrons. Attenuation of gamma photons through materials varies with the atomic number $Z$, the mass density and the thickness of the material or in other words on macroscopic cross sections and material density [5] [6] [7]. Thus materials such as iron, lead, and bismuth are the best for gamma shielding.

Therefore, to make a composite or a mixture of elements which is capable to attenuate both neutrons and gamma rays, the composite or the mixture must contain heavy and light absorbing elements. The choice of elements must consider that the elements have to possess a higher energy loss per collision either through inelastic or elastic collision or a high absorption cross section without emission of high energy gamma rays [8] [9]. In addition, the elements or materials chosen to absorb thermal neutrons must be placed at a position where thermal neutrons are generated or where the neutron flux is high. This means that a homogenous or multilayer shield with the neutron absorbing layer at the end is the optimum choice for composite shield [10] [11] [12]. Extensive work has been devoted for protection purposes against neutrons and gamma rays produced as a result of weapons, nuclear accidents, equipment's associated with radiation therapy and several radiation related industrial or research applications. Composites of natural rubber were prepared with different concentrations of boron carbide powder and subjected to thermal neutron radiation shielding [13]. It is found that, the first $1.5 \mathrm{~cm}$ layer of the composite samples reduced the initial direct slow neutron flux by about $85 \%$ for the composite containing 57 $w t \%$ followed by an exponential decrease in thickness.

A composite of natural rubber mixed with boric acid $\left(\mathrm{H}_{3} \mathrm{BO}_{3} / \mathrm{NR}\right)$ was used to get thermal neutron radiation shielding composites. It was found that the total macroscopic cross-section reaches $0.29 \mathrm{~cm}^{-1}$ at $30 \mathrm{phr}$ of $\mathrm{H}_{3} \mathrm{BO}_{3}$ [14]. An inclusion of lead oxide $\left(\mathrm{PbO}_{2}\right)$ in the shielding block made from a mixture of Boric acid and borax with natural rubber can slightly increase its thermal neutron shielding capability and decrease the effective minimum thickness for gamma shielding [15]. Not only the natural rubber but also Ethylene Propylene Diene Termonomer (EPDM) synthetic rubber is a good candidate material for neutron shielding due to its hydrogen content [16]. Silicone rubbers were originally used during World War II in the military applications because it has a good resistance to the extreme temperature. Over the years, a lot of advances have been done and now, silicone rubbers provide maximum reliability amongst state-of-art elastomers. Whether exposed to adverse environments, stored for prolonged periods or performed under extreme operating conditions, these engineered elas- 
tomers outlive traditional organic rubbers.

Therefore, the aim of the present work is to produce borated silicone rubber composite capable to be used as an emergency personal nuclear radiation shield in the form of wearing clothes taking into consideration the well-known advantages of silicone rubber as compared with other polymers.

\section{Experimental Details}

\subsection{Sample Mix Design and Composition}

Silicone rubber impregnated with different percentage content of boric acid $\left(\mathrm{H}_{3} \mathrm{BO}_{3}\right) ; 9 \%, 17 \%, 23 \%, 29 \%, 33 \%, 38 \%$ by weight, was mixed by a compressive method under temperature of $150^{\circ} \mathrm{C}$ and pressure $4 \mathrm{MPa}$. A rolling machine, type Farrell, Lancashire, England was used to perform the mix of the additives with the silicone rubber. Figure 1 shows the rolling machine which is used for preparation. The sheet of silicon rubber was passed between the two rolls of the machine and at the same time the additives was spattered. Special care was taken to assure the homogeneity of the produced mix. The prepared mix was compressed in the form of sheet of $4 \mathrm{~mm}$ thick; this sheet was used to make samples of 40 by $40 \mathrm{~mm}$ outer dimensions [13].

\subsection{Measurements of Composite Attenuation Properties to Thermal Neutrons}

Two series of measurements were performed to assess the attenuation properties of the mixed materials to thermal neutrons of high and low flux intensities i.e., for position far enough from the source and a position near to the source. These represent a case far from the source and a case near to the source of fission neutrons. For both cases, measurements were performed using a californium-252 source of like fission spectrum. Thermal neutron flux was measured by a $\mathrm{BF}_{3}$ detector.

For case 1, the material under investigation was fixed behind a polypropylene as a fast neutron moderator of $8 \mathrm{~cm}$ thick. The transmitted thermal neutron flux

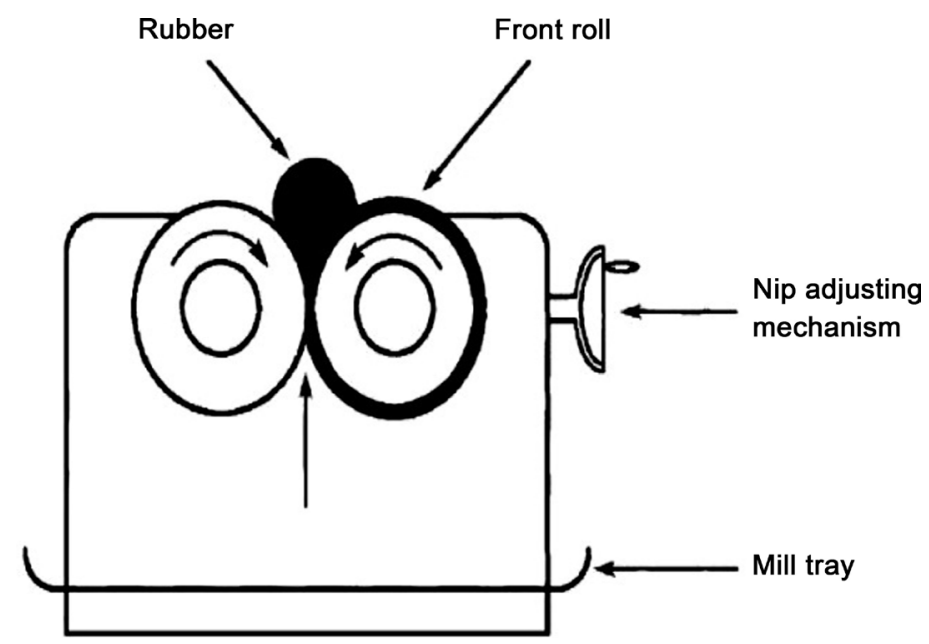

Figure 1. Rolling machine (The two roll mill, Farrell, Lancashire, England). 
was measured with and without cadmium sheet of $1 \mathrm{~mm}$ thick placed before the investigated samples. In case 2, the thermal neutron flux was measured without the polypropylene layer with and without cadmium sheet. Figure 2 shows a layout of the experimental arrangement.

\section{Results and Discussion}

\subsection{Thermal Neutron Attenuation}

There are two types of thermal neutrons; the first type is that initially originated from the neutron source. The second type is that originated from the attenuation and/or moderation process of the initial fast neutron inside the shield.

The measured thermal neutron fluxes (relative values) behind the borate silicone rubber of different thicknesses are shown in Figure 3. The plotted attenua-

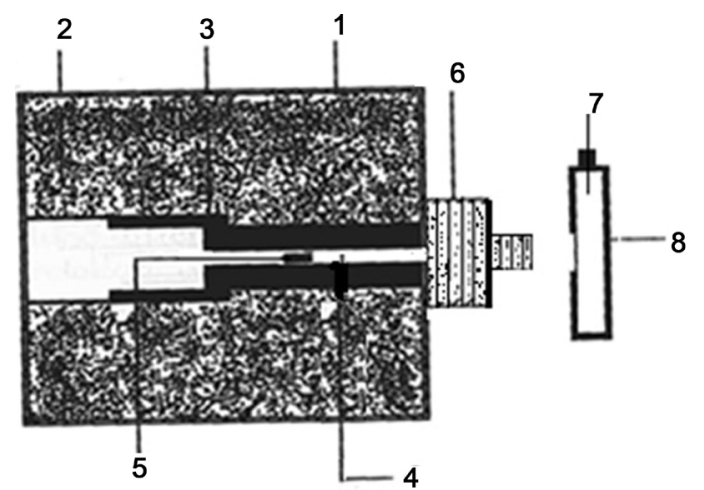

1. Source collimator.

2. High density borated paraffin wax.

3. Lead shield.

4. Radiation beam.

5. Neutron source.

6. Sample under investigation.

7. $\mathrm{BF}_{3}$ detector.

8. ${ }^{113} \mathrm{Cd}$ shield

Figure 2. Block diagram of BF3 detector arrangement.

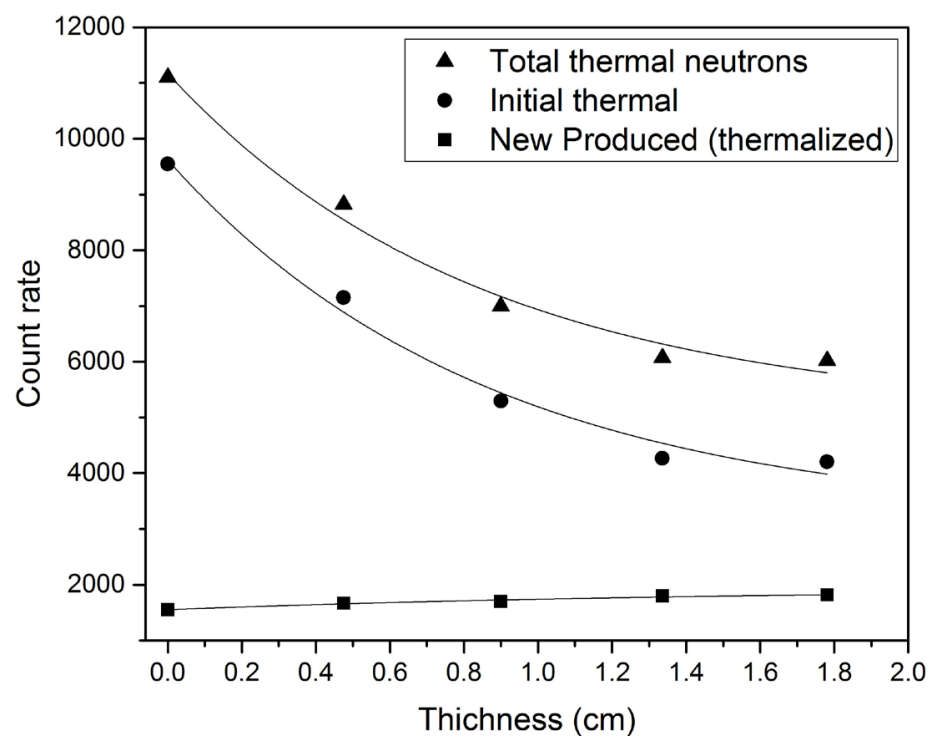

Figure 3. Attenuation of thermal neutron fluxes in silicon rubber. 
tion relations are given for total, initial thermal and new produced thermal neutrons. These relations show that, the flux intensity decreases with increasing sample thickness for both total and initial incident thermal neutrons. However, the measured new produced thermal neutrons do not show the same behavior, they show nearly the same flux value behind the measured thicknesses. The plotted relation for new produced thermal neutron shows that, the flux intensity does not decrease by increasing the sample thickness, but shows a slightly increase. This could be attributed to the fact that, the rate of fast neutron moderation increases by increasing the thickness in spite of being relatively small. The plotted relations also show that the contribution of new produced thermal neutrons is less than $15 \%$ and therefore its contribution to the total absorbed dose is negligible.

\subsection{Attenuation of Thermal Neutron Flux in Borated Silicone Rubber}

Figures 4-7 shows the plotted attenuation relations for total, initial, and new produced thermal neutrons in silicon rubber with $9 \%, 17 \%, 23 \%$, and $29 \%$ concentrations of boric acid by weight. The attenuation relations in these figures show that, they have nearly the same shape and attenuation profile like their counter parts for plain silicone rubber. They also show that the initial incident thermal neutrons give the main contribution in total measured thermal neutron flux. However, the contribution of new produced thermal neutrons is very low and does not show any appreciable change with the increasing of sample thicknesses. These could be attributed to the fact that they are largely dependent on the distribution of fast neutrons passing through the sample material.

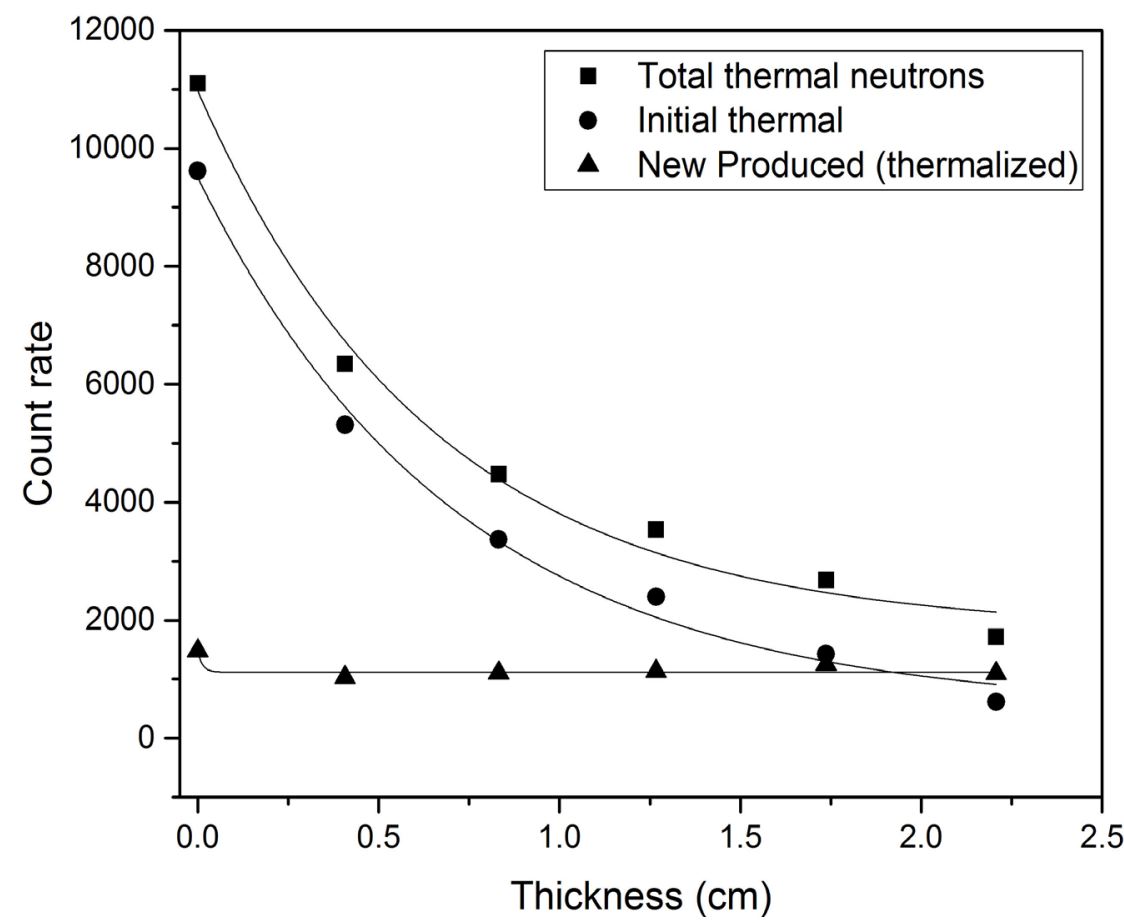

Figure 4. Attenuation of thermal neutron fluxes in silicone rubber with $9 \%$ boric acid. 


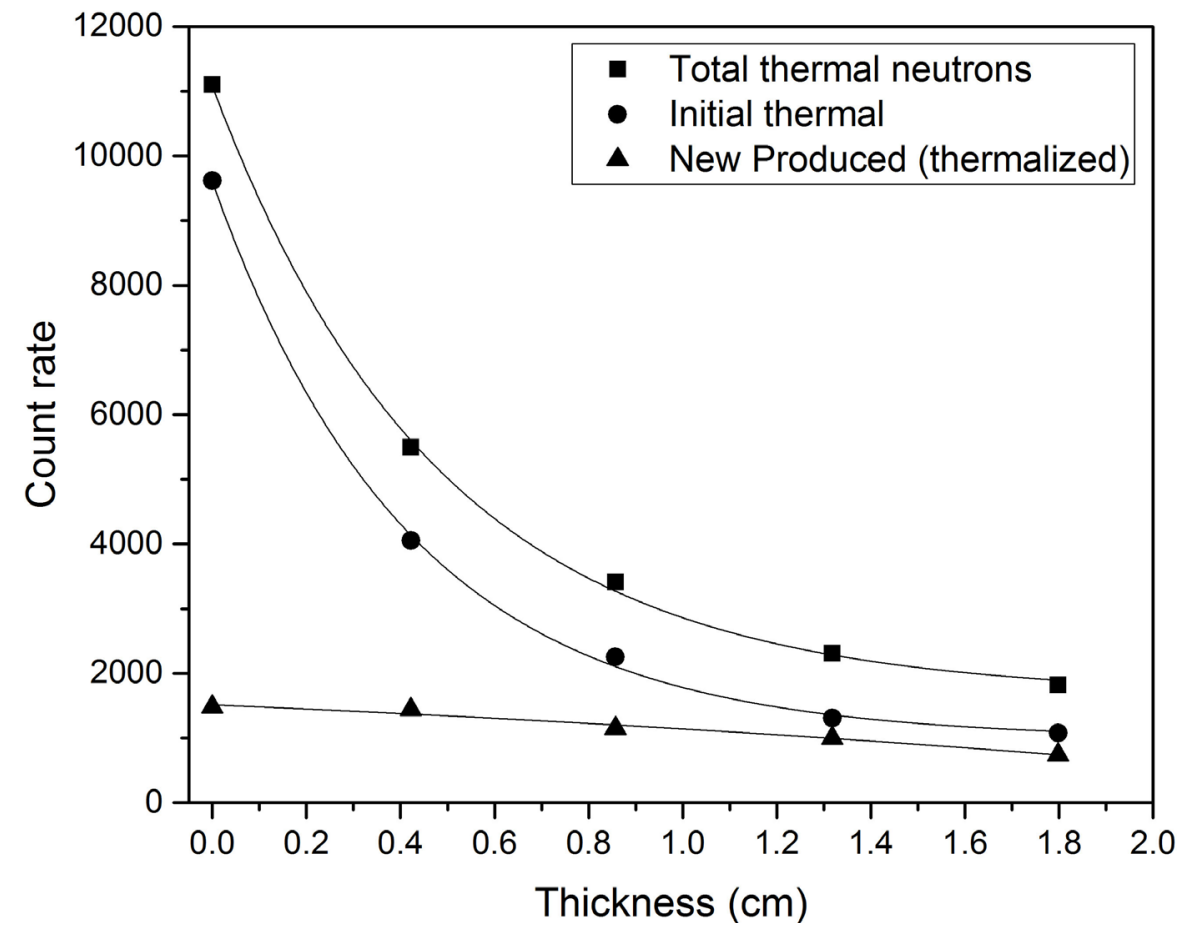

Figure 5. Attenuation of thermal neutron fluxes in silicone rubber with $17 \%$ boric acid.

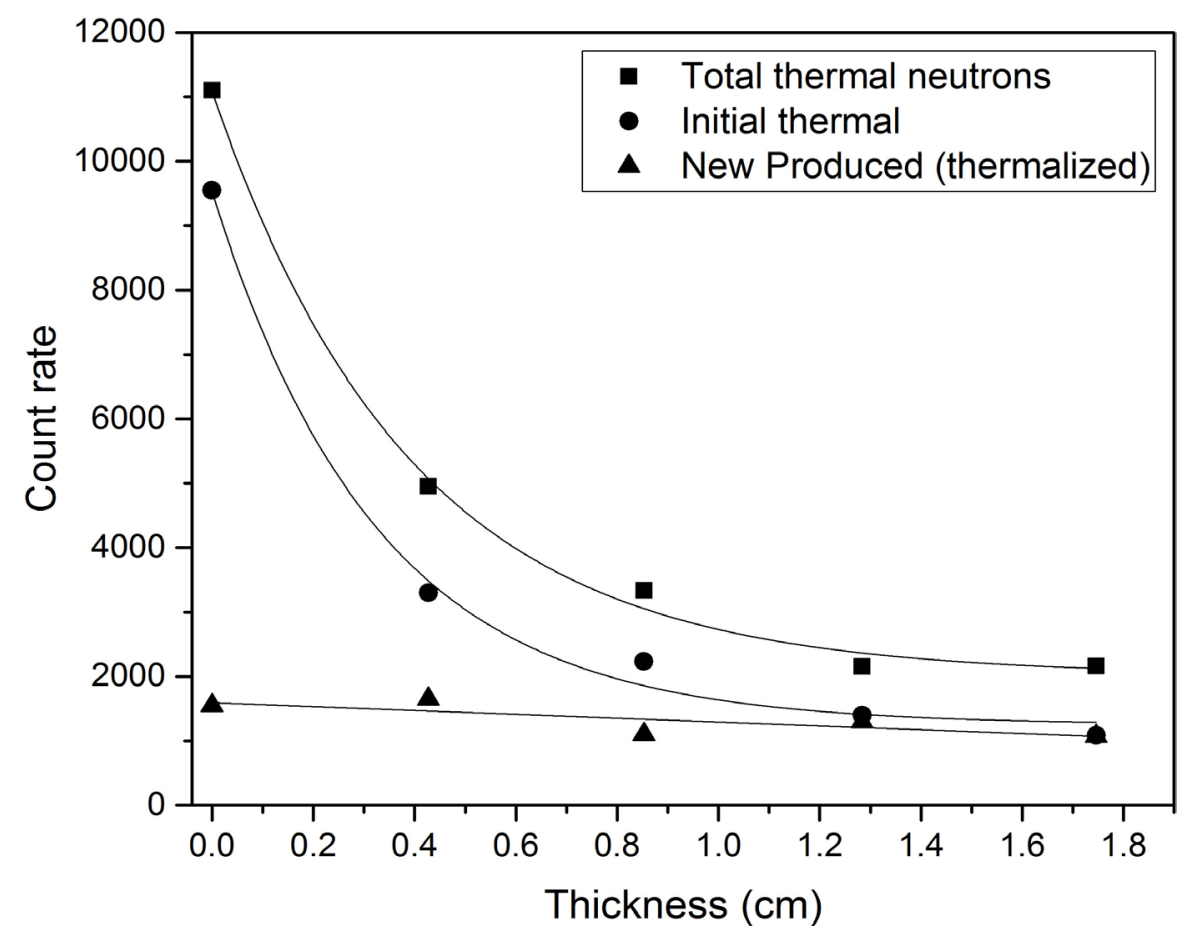

Figure 6. Attenuation of thermal neutron fluxes in silicone rubber with $23 \%$ boric acid.

\subsection{Dependence of Thermal Neutron Flux Distribution on Boron Concentration in Silicone Rubber}

Figure 8 shows the plotted bars for total, initial, and new produced thermal neutron in silicone rubber with different concentrations of boric acid. The presented intensity bars show that the flux intensity of total, initial incident neu- 
trons decreases sharply for silicone rubber with $17 \%$ by weight of boric acid concentration. However, for the others boric acid concentrations $>17 \%$ the decrease is very low and does not show any appreciable difference. They also show that the initial incident thermal neutrons give the main concentration to total

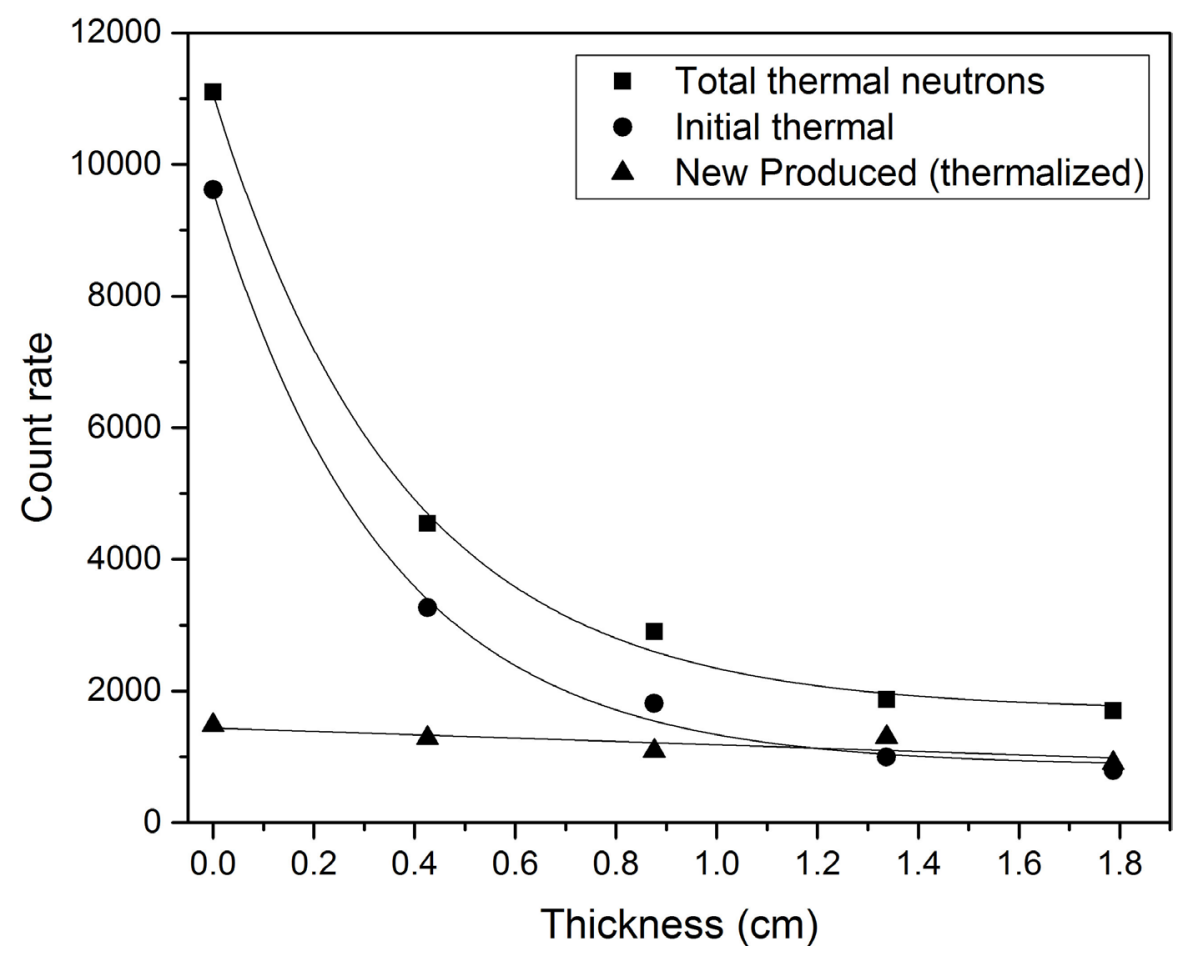

Figure 7. Attenuation of thermal neutron fluxes in silicone rubber with $29 \%$ boric acid.

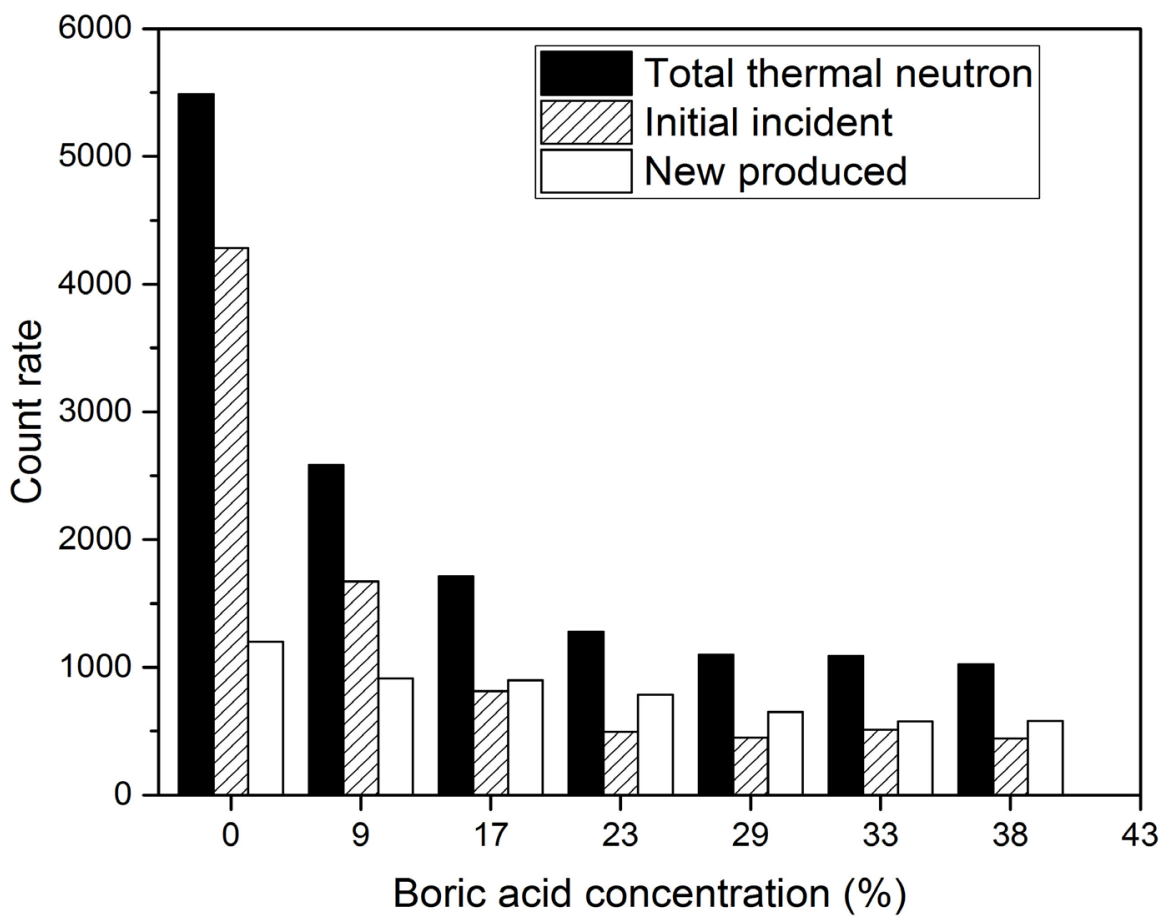

Figure 8. Dependence of thermal neutrons distribution in silicone rubber on different boric acid concentrations. 
thermal neutrons passed through the developed material. Moreover, the borated developed material has slight or negligible effect on the new produced thermal neutrons.

\subsection{Dependence of Attenuation Properties on Neutron Source Position}

Figure 9 shows the plotted flux intensity bars for total, initial, and new produced thermal neutrons measured in silicone rubber for neutron source placed at two positions from the investigated materials. The first position is near to the center of detonation where, the flux intensity of thermal neutrons is very low since the neutrons resulting from fission are mainly fast. The second position is far from the detonation center where the flux intensity of thermal neutrons is high due to the moderation of fast neutrons by the nuclei of light elements and water moisture exists in the atmosphere. The flux intensity bars given in Figure 9, show the flux intensity of measured total, initial and new produced thermal neutrons at two different positions, near and far distance from the source. They also show that at positions far from detonation, the initial thermal neutrons give the main contribution to the total thermal neutrons passed through the investigated material.

\section{Conclusions}

In the present work an experimental intensive study is performed to produce a suitable neutron shielding material to be used as a personal wearing shield. The obtained results can be used to derive the following remarks:

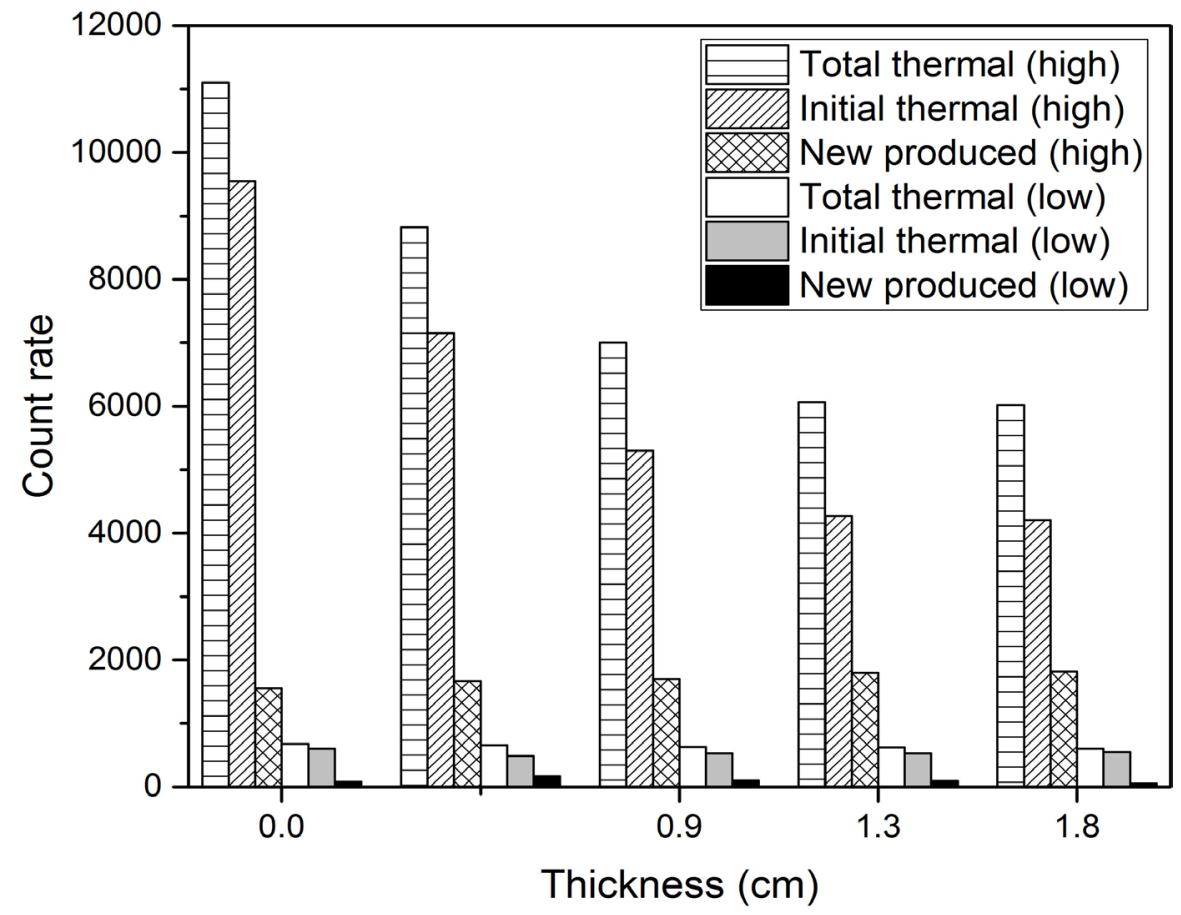

Figure 9. Dependence of thermal neutron fluxes as a function of thickness behind silicone rubber irradiated with high and low fluxes. 
- The total thermal neutron flux penetrated through the developed material decreases with increasing the thickness while the flux intensity of new produced thermal neutron does not show any change. In addition, the contribution of new produced thermal neutrons to the total thermal neutrons is very low or negligible.

- A boron free material thickness of about $10 \mathrm{~mm}$ depresses the neutron flux intensity by more than $40 \%$. However, in case of silicone rubber with $17 \%$ boric acid concentration the depression in flux intensity increases by more than $70 \%$. For higher concentrations no appreciable change was observed.

Finally, the obtained results concerning the neutron shielding properties of the prepared silicone rubber composite a long with its well-known superior thermal \& mechanical properties increase its capability as personal wearing shield.

\section{References}

[1] Chilton, A.B., Shultis, J.K. and Faw, R.E. (1984) Principles of Radiation Shielding. Prentice Hall, Englewood Cliffs.

[2] Kaplan, M.F. (1989) Concrete Radiation Shielding. John Wiley \& Sons, New York.

[3] Profio, A.E. (1979) Radiation Shielding and Dosimetry. John Wiley \& Sons, New York.

[4] Wood, J. (1982) Computational Methods in Reactor Shielding, Pregamon Press, New York.

[5] Singh, V.P. and Badiger, N.M. (2012) Investigation of Gamma and Neutron Shielding Parameters for Borate Glass Containing $\mathrm{NiO}$ and PbO. Physics Research International, 2012, Article ID: 954958.

[6] Amirabadi, E.A., Solimi, M., GhalElaati, N., Eh, G.R. and Asadi, H. (2013) Study of Neutron and Gamma Radiation Protective Shield. International Journal of Innovation and Applied Studies, 3, 1079-1085.

[7] Gwaily, S.E., Badawy, M.M., Hassan, H.H. and Madania, M. (2002) Natural Rubber Composites as Thermal Neutron Radiation Shields: I. B ${ }_{4}$ C/NR Composites. Polymer Testing, 21, 129-133. https://doi.org/10.1016/S0142-9418(01)00058-7

[8] Albert, M.M., Mougel, E. and Zoulatian, A. (2000) Infleuence of Some Parameters of Wood-Cement Preparatiom on Compressive Strength and Dimensional Variation. Proceeding of the International Inorganic-Bonded Wood and Fiber Composites Conference, 7, University of Idaho, US.

[9] Badger, D.M. (2000) Effect of Cellulose Fiber Quality on Cement Board Properties. Proceeding of the International Inorganic-Bonded Wood and Fiber Composites Conference, 7, University of Idaho, US.

[10] Hannant, D.J. (1995) Fiber Reinforcement in the Cement and Concrete Industry. Material Science and Technology, 11, 853-860. https://doi.org/10.1179/mst.1995.11.9.853

[11] Bashter, I.I., Makarious, A.S. and El-Sayed Abdo, A. (1996) Investigation of Hematite-Serpentine and Ilmenite-Limonite Concretes for Reactor Radiation Shielding. Annals of Nuclear Energy, 23, 65-71. https://doi.org/10.1016/0306-4549(95)00011-G

[12] Kanoush, W.A., El-SayedAbdo, A. and Megahid, R.M. (2001) Radiation Shielding Properties of Dolomite and Ilmenite Concretes. 4 th Conference and Workshop on 
Cyclotrones and Applications, Cairo, 17-21 February 2001, 294-308.

[13] Abdel-Aziz, M.M., Gwaily, S.E., Makarious, A.S. and El-Sayed Abdo, A. (1995) Ethylene-Propylene Diene Rubber/Low Density Polyethylene/Boron Carbide Composites as Neutron Shields. Polymer Degradation and Stability, 50, 235-240. https://doi.org/10.1016/0141-3910(95)00177-8

[14] Gwaily, S.E., Hassan, H.H., Badawy, M.M. and Madani, M. (2002) Natural Rubber Composites as Thermal Neutron Radiation Shields $\mathrm{II}-\mathrm{H}_{3} \mathrm{BO}_{3} / \mathrm{NR}$ Composites. Polymer Testing, 21, 513-517. https://doi.org/10.1016/S0142-9418(01)00117-9

[15] Onjun, O., Laothong, N., Picha, R., Ratanathongchai, W. and Onjun, T. (2014) Natural Rubber Blocks as Thermal Neutron Shields. Progress in Nuclear, Science and Technology, 4, 631-634. https://doi.org/10.15669/pnst.4.631

[16] Özdemir, T., Akbay, I.K., Uzun, H. and Reyhancan, I.A. (2016) Neutron Shielding of EPDM Rubber with Boric Acid: Mechanical, Thermal Properties and Neutron Absorption Tests. Progress in Nuclear Energy, 89, 102-109.

https://doi.org/10.1016/j.pnucene.2016.02.007

Submit or recommend next manuscript to SCIRP and we will provide best service for you:

Accepting pre-submission inquiries through Email, Facebook, LinkedIn, Twitter, etc. A wide selection of journals (inclusive of 9 subjects, more than 200 journals)

Providing 24-hour high-quality service

User-friendly online submission system

Fair and swift peer-review system

Efficient typesetting and proofreading procedure

Display of the result of downloads and visits, as well as the number of cited articles

Maximum dissemination of your research work

Submit your manuscript at: http://papersubmission.scirp.org/

Or contact jamp@scirp.org 